\title{
Potentiometric Studies of the Interaction of Bovine Serum Albumin and Poly(dimethyldiallylammonium chloride)
}

\author{
Y-p. Wen and P. L. Dubin*
}

Department of Chemistry, Indiana-Purdue University, Indianapolis, Indiana 46203

Received J uly 30, 1997; Revised Manuscript Received September 30, 1997

\begin{abstract}
Potentiometric and turbidimetric titrations were used to study the interaction between bovine serum al bumin (BSA) and poly(diallyldimethylammonium chloride) (PDADMAC). Binding between $B S A$ and PDADMAC, which takes place only above some critical initial $\mathrm{pH}\left(\mathrm{pH}_{\mathrm{c}}\right)$, leads to a decrease in the $\mathrm{pH}$ of solution, indicating that the interactions enhance the dissociation constant $\mathrm{K}_{\mathrm{a}}$ of the ionizable groups on BSA and result in an increase of the number of net negative charge on the protein. The pH difference caused by the interaction, $\Delta \mathrm{pH}$, decreases with added salt, which indicates that the effect of the interaction on the $\mathrm{pK}_{\mathrm{a}}$ of $\mathrm{BSA}$ increases with a decrease of ionic strength. Protein binding to PDADMAC imposes a stronger influence on the $K_{a}$ of the carboxylic groups than on the $K_{a}$ of the imi dazolium and ammonium groups. The fraction of BSA bound $\left(f_{b}=[B S A]_{b} / C_{p r}\right)$ increases with polymer concentration $C_{p}$ until all BSA are bound. The rate at which $f_{b}$ increases with added polymer at low $C_{p}$ depends on the initial $\mathrm{pH}\left(\mathrm{pH}_{\mathrm{i}}\right)$, consistent with an increase in the binding constant with $\mathrm{pH}_{\mathrm{i}}$. Upon a further increase of $\mathrm{pH}$, phase separation occurs at some well-defined point, $\mathrm{pH}_{\phi}$, which increases with ionic strength. $\mathrm{pH}_{\phi}$ depends strongly on $\mathrm{C}_{\mathrm{p}}$ at fixed BSA concentration, but only weakly on $\mathrm{C}_{\mathrm{p}}$ at constant $r=C_{p r} / C_{p}$. Phase separation may also be observed upon addition of polymer to BSA at $\mathrm{pH}>\mathrm{pH}_{\phi}$. In the range of $\mathrm{pH}_{\mathrm{c}}<\mathrm{pH}<\mathrm{pH}_{\phi}, \mathrm{pH}$ titration and turbidimetry reveal the formation of soluble complexes. However, even when phase separation (coacervation) occurs, no corresponding change in the pH titration curve is observed, indicating that the protein's acid-base equilibria are unperturbed by phase separation.
\end{abstract}

\section{Introduction}

The association of proteins with synthetic polyelectrolytes is interesting for at least three reasons. First, the binding of proteins to DNA is thought to be composed of a nonspecific Coulombic interaction coupled with site-specific short-range effects, and studies of complexation between proteins and synthetic polyions may produce insight into the former, long-range effect. ${ }^{1}$ Second, phase separation of protein-polyelectrolyte complexes offers the possibility of protein purification. ${ }^{2-4}$ Third, polyelectrolytes can be utilized for immobilization and stabilization of enzymes. ${ }^{5}$

Many techniques have been applied to polyelectroIyte- protein complexes, including turbidimetry, viscometry, analytical ultracentrifugation, size-exclusion chromatography, fluorescence spectroscopy, electrophoretic light scattering (ELS), static light scattering, electron-spin resonance, circular dichroism, and dynamic light scattering (QELS). ${ }^{6}$ Most of these methods provide information about the overall structure of the complex, e.g., its hydrodynamic dimensions or radius of gyration. In general, they do not probe the local interaction between polyelectrolyte and protein ionophores, i.e., the effects that take place over a range of several angstroms.

While the experiments referred to above have dealt with many different protein-polyelectrolyte combinations, under a wide range of solution conditions, some generalizations can be made. The predominant interaction between protein and polyelectrolyte is Coulombic, and therefore mainly controlled by protein charge density, $\sigma$ (i.e., via the $\mathrm{pH}$ ), polyelectrolyte charge density, $\xi$, and ionic strength, I. In general, if $\sigma$ and $\xi$ are of the same sign, or if I is large, no interactions occur. Upon a decrease in I, or an increase in $\sigma$ in the opposite direction of $\xi$ (or vice versa), complex formation occurs. Often complexation leads to phase separation \footnotetext{
1997.

${ }^{\otimes}$ Abstract published in Advance ACS Abstracts, November 15,
}

(either precipitation or coacervation) but it appears that a state of soluble complex formation always exists between the regimes of phase separation and noninteraction.

The appearance of turbidity may be remarkably abrupt. For example, solutions of bovine serum al bumin (BSA) and poly(diallyldimethylammonium chloride) (PDADMAC) change from optically clear to opaque in a pH interval of about $0.01 \mathrm{pH}$ units. ${ }^{7}$ This point of phase separation is designated as " $\mathrm{pH}_{\phi}$ ". The transition from noninteracting solution to the soluble complex regime is less striking but nevertheless can be defined (as " $\mathrm{pH}_{\mathrm{c}}$ ") within $0.1 \mathrm{pH}$ units by turbidimetry, QELS, or ELS. ${ }^{8}$ From well-established $\mathrm{pH}$ titration curves for $\mathrm{BSA},{ }^{9}$ the protein net charge can be determined, leading to a mean surface charge density, and thus to values of $\sigma_{\mathrm{c}}$ and $\sigma_{\phi}$. The dependence of $\sigma_{\mathrm{c}}$ on the square root of i onic strength is found to be remarkably linear, ${ }^{10}$ which attests to the electrostatic nature of the interaction, ${ }^{11}$ closely resembling the behavior of polyelectrolytemicelle systems, 12 which also display a linear dependence of $\sigma_{\mathrm{c}}$ on $\sqrt{ } \mathrm{I}$. H owever, the "phase boundary", i.e., $\sigma_{\mathrm{c}} \mathrm{VS} \sqrt{ } \mathrm{I}$, for BSA/PDADMAC, crosses zero at moderate ionic strength, 10 meaning that binding occurs well below the protein isoelectric point in low salt concentrations. This striking result implies the existence of some sort of negative "patch" that binds polycation, even when the net protein charge is positive.

The preceding results suggest the importance of I ocal interactions in the formation of protein-polyel ectrolyte complexes, but the experiments described above generally yield information on the global or long-range properties of the complex. It is to be expected that polyelectrolyte binding must alter the local electrostatic environment of ionizable amino acid residues and thus shift their $\mathrm{pK}_{\mathrm{a}}$ 's, making them more acidic (such pK shifts may be responsible for changes in the enzymatic optimal pH in enzyme-polyelectrolyte complexes). Thus, $\mathrm{pH}$ titration might yield information that is complementary to the scattering or hydrodynamic techniques 
used to date. The simplicity of the $\mathrm{pH}$ titration technique may distract from the value of highly precise titration data, and it is important to emphasize that the potentiometric method provides insight into the shortrange interactions between protein ionophores and polyelectrolytes that may not be available from more instrumentally sophisticated scattering and hydrodynamic methods. In the present work, we focus on the way in which the $\mathrm{pH}$ titration curves of BSA respond to the presence of polycation as a function of $\mathrm{pH}$, ionic strength, and polycation-protein stoichiometry. These results are al so interpreted vis-a-vis the phase changes that may occur concomitantly with $\mathrm{pH}$ change.

\section{Experimental Section}

Materials. Bovine serum albumin (BSA) was from Boe hringer Mannheim Corp. (Indianapolis, IN), purity $\geq 98.5 \%$, MW 68k. Poly(diallyldimethylammonium chloride) (PDADMAC), with $M_{n}=2.4 \times 10^{5}$, was synthesized in the laboratory of W. J aeger, Fraunhofer Inst., Teltow, Germany. Buffer solutions and standard $0.1000 \pm 0.0005 \mathrm{M} \mathrm{NaOH}$ were from Fisher, and $\mathrm{NaCl}$ was from Sigma. All solutions were prepared with $\mathrm{CO}_{2}$-free Millipore-Q water.

Methods. Potentiometric Titration. pH titrations were done with a Beckman $\Phi 34$ meter equipped with a combination el ectrode, under $\mathrm{N}_{2}$, at $24 \pm 1^{\circ} \mathrm{C}$. In "Type 1" titrations, a 2.0 $\mathrm{mL}$ Gilmont microburet was used to add $0.100 \mathrm{M} \mathrm{NaOH}$ to a $15.00 \mathrm{~mL}$ solution of BSA with or without PDADMAC, at a fixed concentration of $\mathrm{NaCl}$. The initial $\mathrm{pH}$ of the BSA solution was adjusted to $4.00 \pm 0.03$. BSA + PDADMAC solutions were prepared by adding the desired amount of PDADMAC to 15.00 $\mathrm{mL}$ of $\mathrm{pH}$-adjusted BSA solutions. These titrations were always accompanied by a blank titration (BSA- and PDADMAC-free, but otherwise perfectly identical to the sample). $\mathrm{pH}$ values were recorded when the meter response was stable to better than $0.01 \mathrm{pH} / \mathrm{min}$. The time required to reach this equilibrium varied from 2 min for optically clear solutions to ca. 2-10 min or more for turbid (coacervate) samples. The reproducibility of repeated titrations was $\pm 0.03 \mathrm{pH}$ units. In "Type 3" titrations, $40 \mathrm{~g} / \mathrm{L}$ PDADMAC in $0.03 \mathrm{M} \mathrm{NaCl}$ was added gradually to $15.00 \mathrm{~mL}$ of $1.0 \mathrm{~g} / \mathrm{L}$ BSA in $0.03 \mathrm{M} \mathrm{NaCl}$, after adjusting both to the desired initial $\mathrm{pH} . \mathrm{pH}=4.00$ and 10.00 buffer solutions were used to calibrate the $\mathrm{pH}$ meter for "Type 1" titrations, and 7.00 and 4.00 for "Type 3" titrations. Meter drift was ca. $0.03 \mathrm{pH}$ unit in $2 \mathrm{~h}$.

Turbidimetric Titrations. Turbidimetric "Type 1" and "Type 3" titrations were carried out with a Brinkman PC 800 col orimeter, equipped with a $1 \mathrm{~cm}$ probe and a $420 \mathrm{~nm}$ filter. The probe was cleaned by immersion in $1 \mathrm{M} \mathrm{HCl}$ under magnetic stirring for a few minutes foll owed by washing with distilled water, and the colorimeter was calibrated to $100 \%$ T with distilled water. Titrations were carried out as described above, and turbidity was reported as $100-\% \mathrm{~T}$. All titrations were carried out with gentle magnetic stirring, and the time interval between measurements was ca. 2 min or more.

\section{Results and Discussion}

Figure 1 presents the raw titration data for BSA (3.0 $\mathrm{g} / \mathrm{L})$, with and without PDADMAC $(0.6 \mathrm{~g} / \mathrm{L})$ at low and moderate ionic strengths. The addition of polycation increases the acidity of titratable groups on the protein. The onset of this effect occurs at an ionic-strengthdependent $\mathrm{pH}$ that is identical to the $\mathrm{pH}$ of incipient complex formation, as determined by turbidimetric and light-scattering techniques, described below and elsewhere. $^{6-8,10}$ The effect, which is quite pronounced at low ionic strength, is barely observable in $0.1 \mathrm{M} \mathrm{NaCl}$, for two reasons. First, the addition of $\mathrm{NaCl}$ elevates the point of complex formation $\left(\mathrm{pH}_{\mathrm{c}}\right) ; i^{10}$ second, we may presume that the influence of bound polycation on the $\mathrm{pK}_{\mathrm{a}}$ of titratable groups, which is fundamentally electrostatic, is diminished in the presence of excess elec-
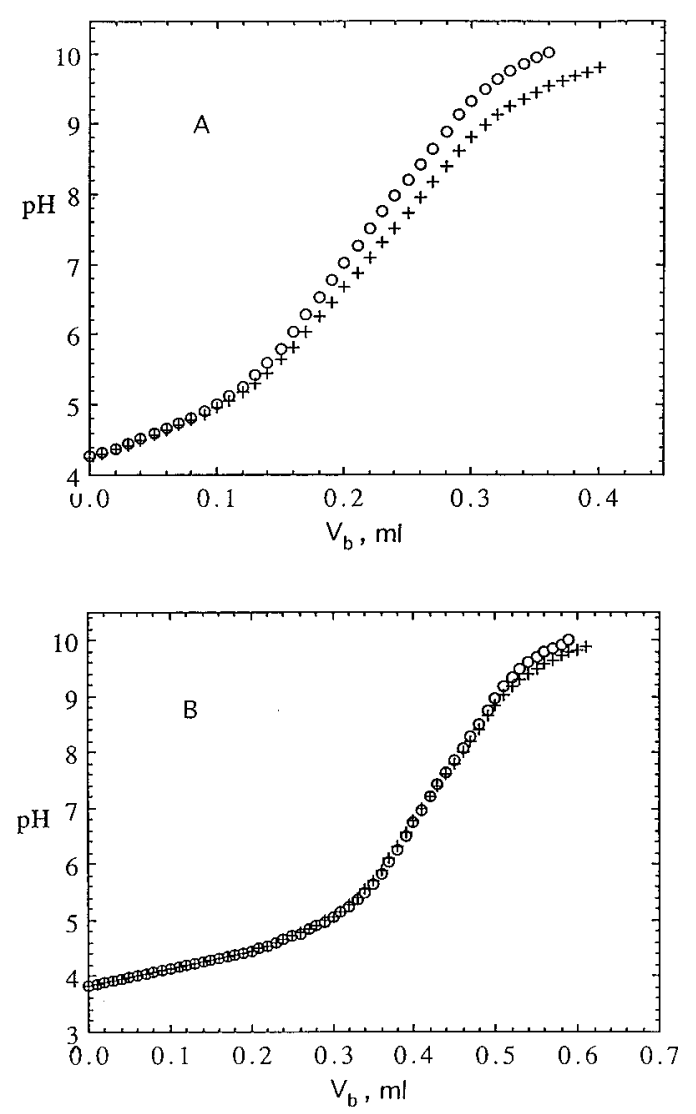

Figure 1. (A) $\mathrm{pH}$ vs volume of $0.100 \mathrm{M} \mathrm{NaOH}$, for (O) $3.0 \mathrm{~g} / \mathrm{L}$ $\mathrm{BSA}$ in $0.03 \mathrm{M} \mathrm{NaCl}$, and $(+)$ same with $0.6 \mathrm{~g} / \mathrm{L}$ PDADMAC $(r$ $=5$ ). (B) Same as for $(A)$, except in $0.10 \mathrm{M} \mathrm{NaCl}$.

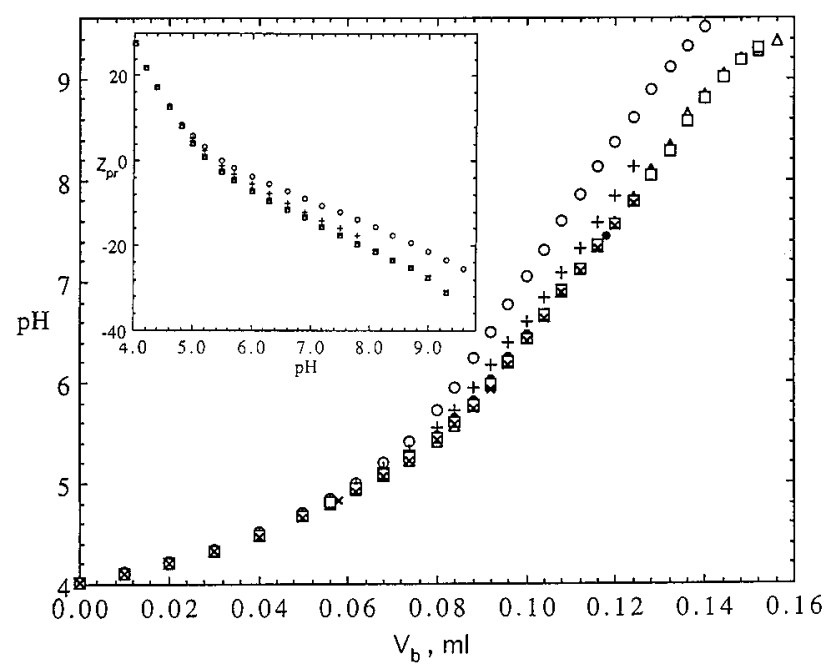

Figure 2. $\mathrm{pH}$ titrations of $\mathrm{BSA}(1.0 \mathrm{~g} / \mathrm{L})$ in $0.03 \mathrm{M} \mathrm{NaCl}$, with and without PDADMAC at various concentrations, $C_{p} . C_{p}(g /$ $\mathrm{L})=(\bigcirc) 0,(+) 0.20,(\times) 0.23,(\bullet) 0.28,(\square) 0.40,(\triangle) 1.00 \mathrm{~g} / \mathrm{L}$. Insert: $Z_{\mathrm{pr}}$ (net protein charge) vs $\mathrm{pH}$.

trolyte. Potentiometric titration therefore is not useful at moderate or high ionic strengths. On the other hand, if the ionic strength is too low, it becomes difficult to take into account the contribution of PDADMAC to I. For these reasons, all subsequent experiments were carried out in $0.03 \mathrm{M} \mathrm{NaCl}$.

Figure 2 shows the influence of polymer concentration $\left(C_{p}=0-1.00 \mathrm{~g} / \mathrm{L}\right)$ on the titration curve of $1.0 \mathrm{~g} / \mathrm{L} \mathrm{BSA}$ in $0.03 \mathrm{M} \mathrm{NaCl}$. The effect of polycation at a given volume of added $\mathrm{NaOH}$ (i.e., at a given degree of neutralization of titratable amino acids), which we report as $\Delta \mathrm{pH}$, increases with $\mathrm{C}_{\mathrm{p}}$ up to $\mathrm{C}_{\mathrm{p}}=0.23 \mathrm{~g} / \mathrm{L}$ 


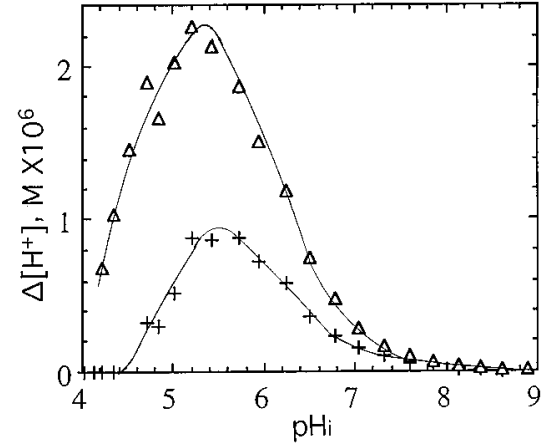

Figure 3. Release of $\left[\mathrm{H}^{+}\right]$arising from addition of PDADMAC, $\mathrm{C}_{\mathrm{p}}=0.20(+)$ or $1.00(\triangle) \mathrm{g} / \mathrm{L}$, as a function of initial $\mathrm{pH}$. [BSA] $=1.0 \mathrm{~g} / \mathrm{L}$, in $0.03 \mathrm{M} \mathrm{NaCl}$.

but remains unchanged at higher polymer concentrations. We may then conclude that the number of compl exed protein molecules increases with $C_{p}$ but that all BSA is bound for $C_{p}>0.28 \mathrm{~g} / \mathrm{L}$. From the published isoionic point of 5.5, ${ }^{13}$ the protein net charge at that $\mathrm{pH}$ is known to be zero; therefore, the titration curves may be presented as net charge vs $\mathrm{pH}$, as in the insert of Figure 2. This result shows that when free and bound proteins are in equilibrium at a fixed $\mathrm{pH}$, the net charge on the latter is more negative, meaning that the negatively charged groups are stabilized by complexation with polycation.

While all solutions in Figure 2 are optically clear at $\mathrm{pH}<6$, turbidity appears rather abruptly in the presence of PDADMAC at higher $\mathrm{pH}$. As will be discussed below, the turbidity increase is sufficiently dramatic to be viewed as indicative of a type of phase transition, the onset of which we refer to as $\mathrm{pH}_{\phi}$, where $\mathrm{pH}_{\phi}$ increases with polymer concentration. This effect corresponds to coacervation, the formation of a dispersed second liquid phase, concentrated in polymer and protein. ${ }^{14}$ At this point, we only note that the $\mathrm{pH}$ titration curves display no change at $\mathrm{pH}_{\phi}$, which suggests that (1) proteins within the coacervate phase are fully titratable and (2) the equilibrium electrode response is unaffected by the presence of coacervate; although, as noted above, stable $\mathrm{pH}$ values are not observed while the coacervation state is changing, as evidenced by changes in turbidity.

The diminution in $\mathrm{pH}$ upon addition of polymer, observed in Figure 2 for $\mathrm{pH}>$ ca. 4.4, must arise from the release of protons by BSA upon binding to PDADMAC. In Figure 3, we show the increased hydrogen ion concentration accompanying the addition of either 0.20 or $1.00 \mathrm{~g} / \mathrm{L}$ PDADMAC to $1.0 \mathrm{~g} / \mathrm{L} \mathrm{BSA}$, as a function of the initial $\mathrm{pH}\left(\mathrm{pH}_{\mathrm{i}}\right)$, and we obtain the result that $\Delta\left[\mathrm{H}^{+}\right]$goes through a maximum with $\mathrm{pH}_{\mathrm{i}}$. This result is expected, in the sense that the extent of polyelectrolyte-protein interaction is low at low $\mathrm{pH}$, while at high $\mathrm{pH}$ titratable groups are already fully ionized and cannot release protons. In the present case we note that $\Delta\left[\mathrm{H}^{+}\right]=[\mathrm{BSA}]_{b} \mathrm{~N}_{\mathrm{H}}$, where $[\mathrm{BSA}]_{\mathrm{b}}$ is the molar concentration of bound protein and $\mathrm{N}_{\mathrm{H}}$ is the average number of protons released into solution per BSA mol ecule upon binding. At fixed ionic strength, $[B S A]_{b}$, which is zero at $\mathrm{pH}<\mathrm{pH}_{\mathrm{c}}$, must increase with $\mathrm{pH}$, because the binding constant must increase as the net protein charge becomes more negative. The maxima in Figure 3 must then indicate a drop in $\mathrm{N}_{\mathrm{H}}$ with $\mathrm{pH}$, for $\mathrm{pH}>$ ca. 5.

It is interesting to note the location of the maxima in Figure 3 at $\mathrm{pH}_{\mathrm{i}} \cong 5.5$, the isoionic point (IP) of BSA.

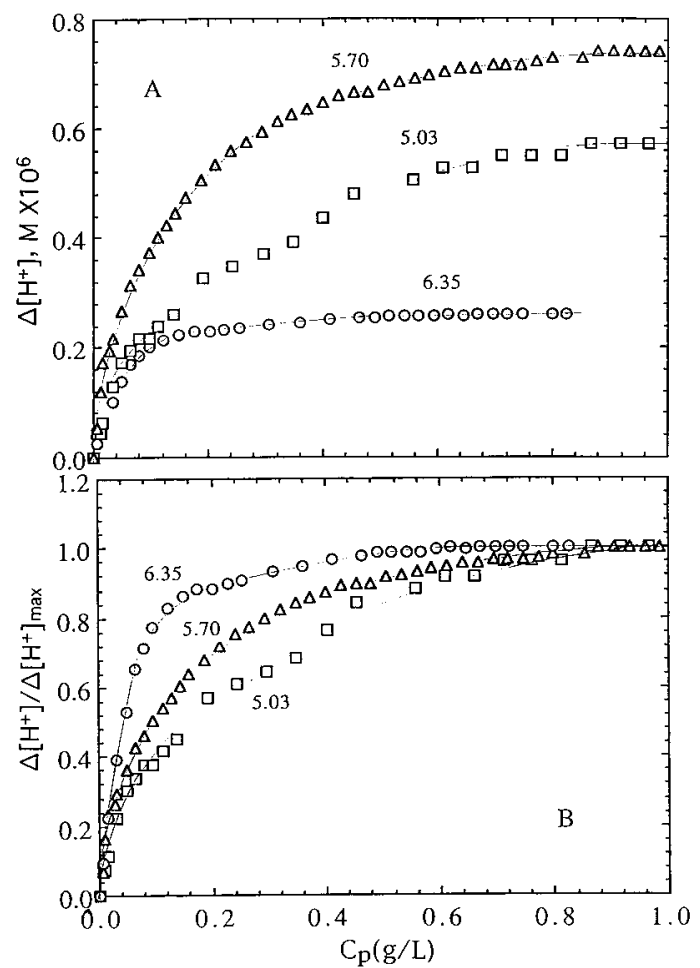

Figure 4. (A) $\Delta\left[\mathrm{H}^{+}\right]$vs $\mathrm{C}_{\mathrm{p}}$ for $\mathrm{BSA}(1.0 \mathrm{~g} / \mathrm{L})+$ PDADMAC, in $0.03 \mathrm{M} \mathrm{NaCl}$ and at different initial pHs: $(\square) \mathrm{pH}_{\mathrm{i}}=5.03 ;(\triangle)$ $\mathrm{pH}_{\mathrm{i}}=5.70$; (O) $\mathrm{pH}_{\mathrm{i}}=6.35$. (B) Data of Figure $4 \mathrm{~A}$, as $\Delta\left[\mathrm{H}^{+}\right] /$ $\Delta\left[\mathrm{H}^{+}\right]_{\max }$ VS $\mathrm{C}_{\mathrm{p}}$.

For this protein, IP essentially separates the neutralization regions of acidic and basic amino acids. Thus, at $\mathrm{pH}_{\mathrm{i}}<5.5$, the addition of polycation influences the $\mathrm{pH}$ by reducing the $\mathrm{pK}_{\mathrm{a}}$ of $-\mathrm{COOH}$, while at high $\mathrm{pH}$ it reduces the $\mathrm{pK}_{\mathrm{a}}$ of imidazolium and ammonium groups. Both $\Delta \mathrm{pK}_{\mathrm{a}}(-\mathrm{COOH})$ and $\Delta \mathrm{pK}_{\mathrm{a}}\left(-\mathrm{NH}_{3}{ }^{+}\right)$can be understood to arise from the effect of bound polyelectrolyte on the electrostatic potential in the vicinity of these ionizable residues. If $\mathrm{N}_{\mathrm{H}}$ drops rapidly as the $\mathrm{pH}$ increases in the vicinity of IP, the result may indicate that $\Delta \mathrm{pK}_{\mathrm{a}}(-\mathrm{COOH})>\Delta \mathrm{pK}_{\mathrm{a}}\left(-\mathrm{NH}_{3}{ }^{+}\right)$. There are at least two explanations for this behavior. First, the configuration of bound polycation may spontaneously adjust so as to maximize the proximity of its cationic repeat units and the $-\mathrm{COO}^{-}$groups on the protein surface, whereas there is no particular reason for the polymer to maximize contacts with $-\mathrm{NH}_{2}$ groups (and certainly not with $-\mathrm{NH}_{3}{ }^{+}$). Secondly, specific interactions (i.e., "salt bridges") might be visualized as stabilizing the basic form of carboxylic groups; with regard to basic residues, we can only propose the more indirect effect to lowering the negative potential arising from neighboring carboxylates. Such considerations may explain how binding of polycation can have a stronger effect on $\Delta \mathrm{pK}_{\mathrm{a}}(-\mathrm{COOH})$ than on $\Delta \mathrm{pK}_{\mathrm{a}}\left(-\mathrm{NH}_{3}{ }^{+}\right)$, so that $\mathrm{N}_{\mathrm{H}}$ is substantially larger below IP.

Figure 4 presents the results of "Type 3" titrations, in which polymer is added to BSA at constant ionic strength and nearly constant protein concentration. The asymptotic behavior of these plots shows the point at which saturation occurs and all protein is bound. The rate at which this saturation point is approached is most clearly seen in the normalized curves of Figure $4 B$; here, the initial slopes may be considered a reflection of the binding constant, which appears to increase with initial $\mathrm{pH}$, as expected. The fact that the curve for $\mathrm{pH}_{\mathrm{i}}=5.03$ is intermediate between the curves for 5.70 and 6.35 in Figure 4A may be considered in the light of the preced- 


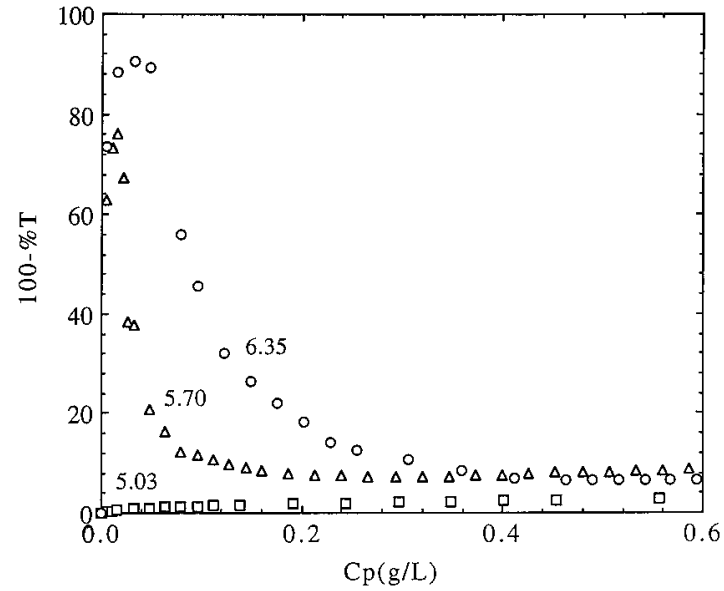

Figure 5. "Type 3" turbi dimetric titration at different initial pHs: $(\square) \mathrm{pH}_{\mathrm{i}}=5.03 ;(\triangle) \mathrm{pH}_{\mathrm{i}}=5.70 ;(\bigcirc) \mathrm{pH}_{\mathrm{i}}=6.35$.

ing discussion about the maxima in Figure 3. Although the binding constant may in fact be largest at $\mathrm{pH}_{\mathrm{i}}=$ 6.35, the absence of ionizable $\mathrm{COOH}$ groups at this $\mathrm{pH}$ can result in a small value for $\mathrm{N}_{\mathrm{H}}$, so that the absol ute change in $\left[\mathrm{H}^{+}\right]$is relatively small. $\Delta\left[\mathrm{H}^{+}\right] / \Delta\left[\mathrm{H}^{+}\right]_{\max }$ is the number of "polycation bound" ("bound" is not strictly defined) carboxylic acid groups at any polymer concentration relative to the number when the polymer concentration is in excess, i.e., when all protein is bound. If we make the reasonable assumption that the number of protons released upon BSA binding (at fixed ionic strength and initial $\mathrm{pH}$ ) is not a function of polymer concentration, then we can also state that $\Delta\left[\mathrm{H}^{+}\right] / \Delta$ $\left[\mathrm{H}^{+}\right]_{\max }$ is the number of "polycation bound" protein molecules at any polymer concentration relative to the total amount, i.e., $\Delta\left[\mathrm{H}^{+}\right] / \Delta\left[\mathrm{H}^{+}\right]_{\max } \propto \mathrm{N}_{\mathrm{b}}$. Thus, $\Delta\left[\mathrm{H}^{+}\right] /$ $\Delta\left[\mathrm{H}^{+}\right]_{\max }=[\mathrm{BSA}]_{\mathrm{b}} / \mathrm{C}_{\mathrm{pr}}=[\mathrm{BSA}]_{\mathrm{b}} /[\mathrm{BSA}]_{\text {total }}$, i.e. the fraction of BSA bound. This supposes a uniform binding mechanism for all protein, independent of polymer concentration. However, as will be shown below, the phase state of the system can change with polymer concentration, $\mathrm{C}_{\mathrm{p}}$, at constant $\mathrm{pH}_{\mathrm{i}}$. Therefore, the aggregation state (number of polymer chains per particle) may also depend on $C_{p}$. At present, it is not known whether $\mathrm{N}_{\mathrm{H}}$ may depend on the degree of aggregation of "primary complexes", but no evidence of such effects can be seen in the curves of Figure 2.

Turbidimetric “Type 3" titrations, shown in Figure 5, also reveal the occurrence of coacervation noted above. At $\mathrm{pH}_{\mathrm{i}}=5.03$, the addition of polymer results in a gradual increase in turbidity, but no phase separation. We can then conclude that only soluble compl exes form and that their concentration increases with $C_{p}$. F or the higher $\mathrm{pH}_{\mathrm{i}}$ 's, the addition of polymer results in a very rapid turbidity increase, followed by a sharp maximum. Subsequently, the turbidity declines to values that we ascribe to soluble complexes. To some extent, these results may be understood in terms of the net charge of PDADMAC-BSA complexes. At $\mathrm{pH}_{\mathrm{i}}=5.03$, the net charge of BSA is close to zero, so that complexes have a large positive charge, which interferes with higher aggregation. At $\mathrm{pH}_{\mathrm{i}}=5.70$ or 6.35 , the net protein charge is negative, and neutralization of the polycation charge may occur upon complexation. Such complexes may aggregate and even coacervate. It is important to point out the distinction between the microscopic stoichiometry (the ratio of bound protein to polymer molecules in a complex) and the bulk or mixing stoichiometry. While these two may be nearly equal in salt-free solutions, ${ }^{15}$ electrophoretic light scattering of the BSA-

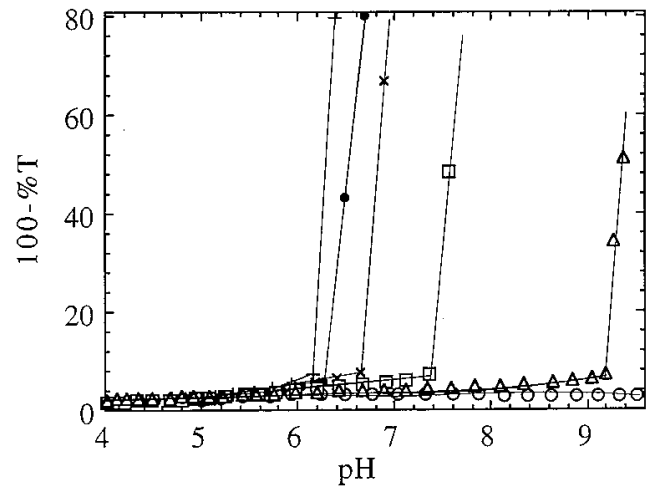

Figure 6. "Type 1 " turbidimetric titration of BSA $(1.0 \mathrm{~g} / \mathrm{L})$ and PDADMAC in $0.03 \mathrm{M} \mathrm{NaCl}, \mathrm{C}_{\mathrm{p}}(\mathrm{g} / \mathrm{L})=(0) 0,(+) 0.20,(\times)$ 0.23, (๑) 0.28, ( $\square) 0.40,(\triangle) 1.00$.

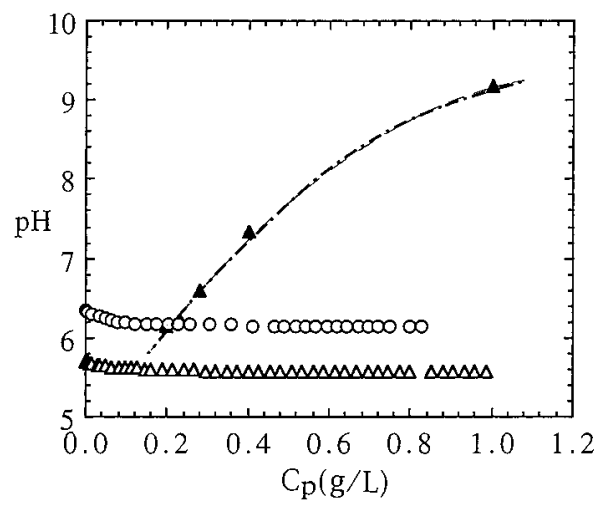

Figure 7. "Type 3 " titrations as $\mathrm{pH}$ vs $\mathrm{C}_{\mathrm{p}}$, for $\mathrm{pH}_{\mathrm{i}}=(0) 6.35$ and $(\triangle)$ 5.70. [( $\mathbf{\Delta}) \mathrm{pH}_{\phi}$ vs $\left.\mathrm{C}_{\mathrm{p} .}\right]$

PDADMAC complex in dilute $\mathrm{NaCl}$ clearly shows the presence of free polymer until protein is in large excess. ${ }^{16}$ Thus the ratio of protein to polymer in complexes can be significantly larger than the bulk ratio, and charge neutralization of complexes is possible even when the bulk stoichiometry is far from charge equality. Furthermore, the microscopic stoichiometry of these complexes is not fixed but depends to some extent on the bulk stoichiometry. This is in contrast to situations where "stoichiometric complexes" form, such as reported by Kabanov et al. for complexation of BSA with quaternized poly(vinylpyridine). ${ }^{17}$ Therefore, complexes formed at excess PDADMAC may acquire a net positive charge and redisperse. They may, however, still exist as higher-order aggregates, which accounts for the larger turbidities observed at high $C_{p}$ relative to solutions at $\mathrm{pH}_{\mathrm{i}}=5.03$.

In order to further analyze the phase separation behavior, "Type 1" turbidimetric titrations were conducted in $0.03 \mathrm{M} \mathrm{NaCl}$, at $C_{p}=0.20,0.23,0.28,0.40$, and $1.00 \mathrm{~g} / \mathrm{L}$ PDADMAC, all with $1.0 \mathrm{~g} / \mathrm{L}$ BSA, with the results shown in Figure 6 . To the extent that protein molecules are distributed among the available polymer chains, the results can be understood on the basis of stoichiometry. At high $C_{p}$, the number of proteins bound per polymer chain, $n_{b}$, is small. If phase separation has as a prerequisite charge neutralization, a higher $\mathrm{pH}$ is required to bring the net charge of "primary complexes" near zero. Thus, $\mathrm{pH}_{\phi}$ increases with $\mathrm{C}_{\mathrm{p}}$. This dependence of $\mathrm{pH}_{\phi}$ on $\mathrm{C}_{\mathrm{p}}$ is shown in Figure 7, in which the broken line represents a type of phase boundary: above this line, the system forms a coacervate phase. Also shown is the dependence of $\mathrm{pH}$ on $\mathrm{C}_{\mathrm{p}}$ for an initial $\mathrm{pH}$ of 6.35 . The intersection of these two curves shows that the system should pass from a 


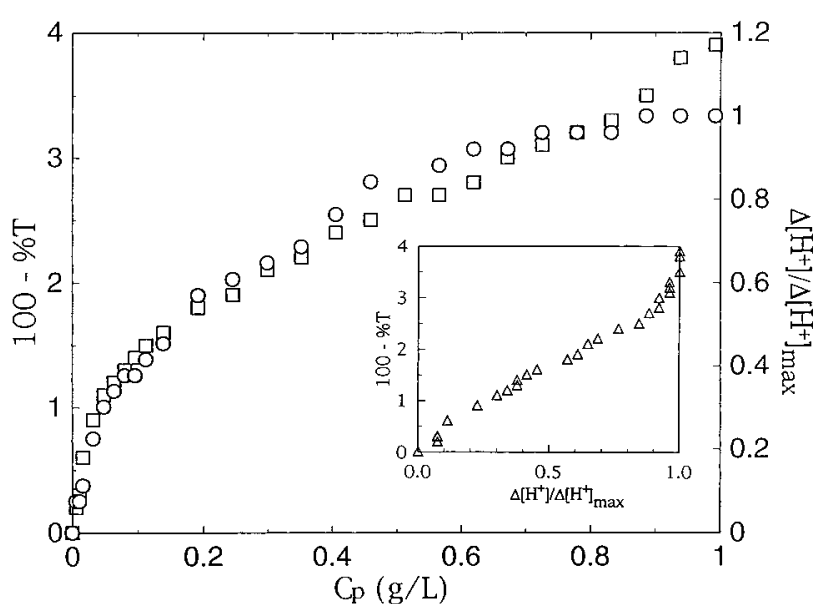

Figure 8. Dependence on $C_{p}$ of turbidity (100 - \%T) ( $\square$ ), and $\Delta\left[\mathrm{H}^{+}\right] / \Delta\left[\mathrm{H}^{+}\right]_{\max }(\mathrm{O})$ for $1.0 \mathrm{~g} / \mathrm{L}$ BSA in $0.03 \mathrm{M} \mathrm{NaCl}$, initial $\mathrm{pH}$ 5.03. Insert: $100-\% \mathrm{~T}$ vs $\Delta\left[\mathrm{H}^{+}\right] / \Delta\left[\mathrm{H}^{+}\right]_{\max }$.

two-phase to a one-phase state at $C_{p} \cong 0.22 \mathrm{~g} / \mathrm{L}$, which is entirely consistent with the plot for $\mathrm{pH}_{\mathrm{i}}=6.35$ in Figure 5. For $\mathrm{pH}_{\mathrm{i}}=5.70$, we see in Figure 5 that coacervate redissolution occurs at ca. $C_{p}=0.1 \mathrm{~g} / \mathrm{L}$, consistent with the probable intersection of the extrapolated phase boundary curve with the lower data set in Figure 7.

Turbidimetric and potentiometric "Type 3" titrations at $\mathrm{pH}_{\mathrm{i}}=5.03$ are compared in Figure 8. With an arbitrary scale adjustment, the turbidity change is remarkably congruent with the degree of complexation, as measured by $\Delta\left[\mathrm{H}^{+}\right] / \Delta\left[\mathrm{H}^{+}\right]_{\max }$. This is shown more clearly in the insert of Figure 8. If, as discussed above, we assume that $\mathrm{N}_{\mathrm{H}}$ is not a function of polymer concentration but depends only on the initial $\mathrm{pH}$, then we can write that $\Delta\left[\mathrm{H}^{+}\right] / \Delta\left[\mathrm{H}^{+}\right]_{\max } \propto \mathrm{N}_{\mathrm{b}}$. Thus, we observe that $\mathrm{N}_{\mathrm{b}}$ increases rapidly at first with $\mathrm{C}_{\mathrm{p}}$ and then approaches an asymptote. At the same time, we note the region $0.2 \mathrm{~g} / \mathrm{L}<\mathrm{C}_{\mathrm{p}}<0.8 \mathrm{~g} / \mathrm{L}$, in which (a) the turbidity increases linearly with $C_{p}$ and $(b)$ the turbidity is linear with $\Delta\left[\mathrm{H}^{+}\right] / \Delta\left[\mathrm{H}^{+}\right]_{\max }$. In this region, the structure of the complexes may be relatively invariant. This result is consistent with the formation of a welldefined complex whose structure is independent of polymer concentration. In this case, the number of complexes formed, $\mathrm{N}_{\mathrm{x}}$, depends linearly on the number of proteins bound, $\mathrm{N}_{\mathrm{b}}$. Thus, $\mathrm{N}_{\mathrm{b}} \propto \mathrm{N}_{\mathrm{x}}$, and the ratio is constant, i.e., $\mathrm{N}_{\mathrm{b}} / \mathrm{N}_{\mathrm{x}}=\overline{\mathrm{n}}_{\mathrm{b}}$, the mean number of proteins per complex, is invariant. The scattering intensity, and hence the turbidity (linear with $100-\% T$ in this range of transmittance), varies linearly with $\mathrm{N}_{\mathrm{x}}$, while $\mathrm{N}_{\mathrm{b}}$ is proportional to $\Delta\left[\mathrm{H}^{+}\right] / \Delta\left[\mathrm{H}^{+}\right]_{\max }$. Consequently, turbidity is linear with $\Delta\left[\mathrm{H}^{+}\right] / \Delta\left[\mathrm{H}^{+}\right]_{\max }$ as shown. (This discussion assumes that complexes are intrapolymer, so that $\bar{n}_{b}=N_{b} / N_{x}$ is both the number of proteins bound per complex and the number of proteins bound per complexed polymer chain). However, if aggregation occurs, then complex structure is variable and we can no longer assume that the scattering intensity is linear with $\mathrm{N}_{\mathrm{x}}$ (or with $\mathrm{N}_{\mathrm{b}}$ ). This seems to be the case for high $\mathrm{pH}_{\mathrm{i}}$, where phase separation is observed. Finally, we note the abrupt increase in turbidity observed at $\mathrm{C}_{\mathrm{p}}>\mathrm{ca}$. $0.8 \mathrm{~g} / \mathrm{L}$, where $\Delta\left[\mathrm{H}^{+}\right] / \Delta\left[\mathrm{H}^{+}\right]_{\text {max }}$ has reached an asymptotic value. This result suggests that, after all BSA is bound, additional polycation can adsorb to the complexes and induce aggregation.

Figure 9 shows that $\mathrm{pH}_{\phi}$ increases with decreasing $r$ but only weakly depends on $C_{p}$ at constant $r$. The effect

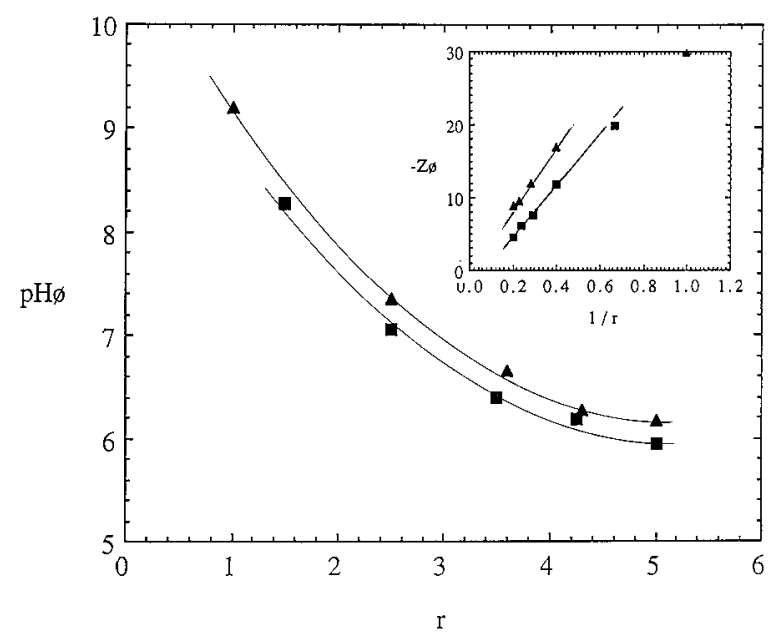

Figure 9. $\mathrm{pH}_{\phi}$ vs $\mathrm{r}$ for $1.0 \mathrm{~g} / \mathrm{L} \mathrm{BSA}$ in $0.03 \mathrm{M} \mathrm{NaCl}$, at various $\mathrm{C}_{\mathrm{pr}}=(\mathbf{\Delta}) 1.0 \mathrm{~g} / \mathrm{L}$, (口) $3.0 \mathrm{~g} / \mathrm{L}$. Insert: $-\mathrm{Z}_{\phi}$ vs $1 / \mathrm{r}$.

Table 1. Effect of Ionic Strength on $\mathbf{p H}_{\phi}$ at Constant $\mathbf{r}$ $\left(C_{p r}=3.0 g / L\right)$

\begin{tabular}{ccc}
\hline$r$ & {$[\mathrm{NaCl}], \mathrm{M}$} & $\mathrm{pH}_{\phi}$ \\
\hline 5.0 & 0.03 & 5.94 \\
5.0 & 0.10 & 7.26 \\
0.5 & 0.03 & 9.50 \\
0.5 & 0.10 & 9.96
\end{tabular}

of $\mathrm{r}$ on $\mathrm{pH}_{\phi}$ can be rationalized in the following way. Coacervation may resemble a phase transition if the product (coacervate) can form only by the reaction of a large number of species and these species may be recognized as "primary" or "intrapolymer complexes" close to electrical neutrality. Since the net charge on a primary complex is $Z_{p}+\bar{n}_{b} Z_{p r}$, then microscopic neutrality of a single complex requires that

$$
\overline{\mathrm{n}}_{\mathrm{b}}=-\mathrm{Z}_{\mathrm{p}} / \mathrm{Z}_{\phi}
$$

where $Z_{\phi}$ is the protein charge at the point of phase separation and $\bar{n}_{b}$ is the mean number of proteins bound in an intrapolymer complex.

By definition,

$$
\bar{n}_{b}=N_{b} /\left(q N_{p r, T} / r-N_{P, f}\right)
$$

where $\mathrm{q}=\mathrm{M}_{\mathrm{BSA}} / \mathrm{M}_{\text {PDADMAC}}, \mathrm{N}_{\mathrm{P}, \mathrm{f}}$ is the number (moles) of free polymer in the system, and the first term in the denominator is simply the total number of moles of polymer in the system. Combining (1) and (2),

$$
-Z_{\phi} / Z_{P}=1 / r\left(q N_{p r, T} / N_{b}\right)-N_{P, f} / N_{b}
$$

The second term on the right should approach zero at large $r$, which suggests a $1 / r$ dependence of $Z_{\phi}$. As shown in the insert of Figure 9 , this prediction is confirmed by the data. The linear dependence in the region $0.2<1 / r<0.4$ is somewhat surprising: because $\mathrm{q}$ and $\mathrm{N}_{\mathrm{pr}, \mathrm{T}}$ are constant, this suggests that $\mathrm{N}_{\mathrm{b}}$ varies little with $\mathrm{C}_{\mathrm{p}}$.

F rom Table 1, we can see that $\mathrm{pH}_{\phi}$ strongly decreases with a reduction of ionic strength. This is because a decrease of ionic strength diminishes the shielding of charges on both BSA and PDADMAC molecules.

\section{Conclusions}

(1) Binding between BSA and PDADMAC leads to a decrease in $\mathrm{pH}$, indicating that the interactions enhance the $\mathrm{K}_{\mathrm{a}}$ of the ionizable groups on BSA and increase the 
net negative charge on BSA. (2) The fraction of BSA bound increases with $C_{p}$ until all BSA is bound. The binding affinity increases with $\mathrm{pH}$. (3) The $\mathrm{pH}$ difference caused by the interaction, $\Delta \mathrm{pH}$, increases with a decrease of ionic strength, which indicates that the influence of complex formation on the $\mathrm{pK}_{a}$ of $\mathrm{BSA}$ increases with a decrease of ionic strength. (5) Complex formation imposes a stronger influence on the $K_{a}$ of the carboxylic groups than on the $\mathrm{K}_{\mathrm{a}}$ of the imidazolium and ammonium groups. (6) The critical point of coacervation, $\mathrm{pH}_{\phi}$ decreases with the ratio of protein to polymer $(r)$, increases with $1 / l$, and depends weakly on $C_{p}$ at constant $r$. The number of proteins bound per complexed polymer chain is sensitive to $r$.

Acknowledgment. This research was supported by grant DMR-9619722 from The National Science Foundation.

\section{References and Notes}

(1) The basis for describing the nonspecific interaction of DNAbinding proteins as purely electrostatic is the magnitude of the effect of ionic strength on the binding, including total suppression at ionic strengths on the order of $1 \mathrm{M}$. See, for example: Shaner, S. L.; Melancon, P.; Lee, K. S.; Burgess, R. R.; Record, M. T., J r. Cold Spring Harbor Symp. Quant. Biol. 1983, 47, 463.

(2) Morawetz, H.; Hughes, W. L. J . Phys. Chem. 1952, 56, 64.

(3) Zhao, J.; Ford, C. F.; Glatz, C. E.; Rougvie, M. A.; Gendel, S. M. J. Biotechnol. 1990, 14, 273.

(4) Dubin, P. L.; Gao, J .; Mattison, K. Sep. Purif. Methods 1994, $23,1$.

(5) Margolin, A.; Sheratyuk, S. F.; Izumrudov, V. A.; Zezin, A. B.; Kabanov, V. A. Eur. J . Biochem. 1985, 146, 625.
(6) For review, see: Xia, J .; Dubin, P. L. In Macromolecular Complexes in Chemistry and Biology; Dubin, P. L., Bock, J., Davis, R. M., Schulz, D. N., Thies, C., Eds.; Springer Verlag: Berlin, 1994; Chapter 15.

(7) Okazaki, T.; Kaibara, K. Unpublished work.

(8) (a) Park, J. M.; Muhoberac, B. B.; Dubin, P. L.; Xia, J. Macromol ecules 1992, 25, 290. (b) Xia, J .; Dubin, P. L.; Kim, Y.; Muhoberac, B. B.; Klimkowski, V.J .J . Phys. Chem. 1993, $97,4528$.

(9) Tanford, C. J . Am. Chem. Soc. 1950, 72, 441.

(10) Mattison, K. W.; Brittain, I.J .; Dubin, P. L. Biotechnol. Prog. 1995, 11, 632

(11) Several theoretical treatments of the interaction of polyelectrolytes with oppositely charged surfaces have appeared. All lead to the appearance of a bound state at some set of critical conditions, defined in terms of $\sigma, \xi$, and I. See, for example: (a) Wiegel, F. W. J . Phys. A: Math. Gen. 1977, 10, 299. (b) Evers, O. A.; Fleer, G. J .; Schuetjens, J . M. H. M.; Lyklema, J . J . Colloid Interface Sci. 1986, 111, 446. (c) Muthukumar M. J . Chem. Phys. 1987, 86, 7230. (d) Odijk, T. H. Langmuir 1991, 7, 1.

(12) McQuigg, D. W.; Kaplan, J . I.; Dubin, P. L. J . Phys. Chem. 1992, 96, 1973.

(13) Tanford, C.; Swanson, S. A.; Shore, W. S. J . Am. Chem. Soc. 1955, 77, 6414.

(14) Dubin, P. L.; Ross, T. D.; Sharma, I.; Yegerlehner, B. E. In Ordered Media in Chemical Separations; Hinze, W. L. Armstrong, D. W., Eds.; ACS Symposium Series No. 342; American Chemical Society: Washington, DC, 1987; Chapter 8.

(15) Tsuboi, A.; Izumi, T.; Hirata, M.; Xia, J ; Dubin, P. L.; Kokufuta, E. Langmuir 1996, 12, 6295.

(16) Li, Y.; Mattison, K. W.; Dubin, P. L.; Havel, H.; Edwards, S. L. Biopolymers 1996, 38, 527.

(17) Kabanov, V. A.; Zezin, A. B.; Mustafaev, M. I.; Kasaikin, V. A. In Polymeric Amines and Ammonium Salts; Goethals, E. J., Ed.; Pergamon: Oxford, U.K., 1980; pp 173-192.

MA971152Q 